\title{
Fractional flow reserve (FFR)-based therapy in patients presenting with acute coronary syndrome: Current data and everyday practice
}

\author{
Grzegorz Zuk ${ }^{1}$, Dariusz Ciecwierz ${ }^{1}$, Natalia Cwalina ${ }^{1}$, \\ Marcin Gruchala ${ }^{1}$, Florim Cuculi ${ }^{2}$ \\ ${ }^{1}$ Interventional Cardiology, First Department of Cardiology, \\ Medical University of Gdansk, Gdansk, Poland \\ ${ }^{2}$ Department of Cardiology, Luzerner Kantonsspital, Luzern, Switzerland
}

\begin{abstract}
Fractional flow reserve (FFR) is an evidence-based diagnostic tool of physiological significance of coronary artery stenosis in patients with stable coronary artery disease (CAD). Due to microvascular dysfunction in acute coronary syndrome (ACS), information obtained from FFR assessment could be less reliable and, thus, its clinical role remains controversial. Indeed, results of currently published studies are essentially discrepant. Only a few randomized clinical trials have been performed showing the efficacy of FFR-guided percutaneous coronary intervention in ACS. Consequently, its role in acute scenarios remains substantially understudied. Herein, is presented the current state of knowledge regarding FFR use in ACS setting. (Cardiol J 2017; 24, 4: 426-435)
\end{abstract}

Key words: fractional flow reserve, acute coronary syndrome, hyperemia, coronary revascularization, microcirculation

\section{Introduction}

Fractional flow reserve (FFR)-guided percutaneous coronary intervention (PCI) [1,2] improves long-term outcome and reduces cost in coronary artery disease (CAD) settings as compared with angiographic-guided PCI [3, 4]. The value of FFR is an integrated way associated with an ability to produce maximal hyperemia to achieve a linear relation between pressure and flow [5, 6]. Maximal hyperemia in FFR assessment is a simulation of the working heart in physical effort conditions under the influence of potent vasodilators [5, 7]. Due to microcirculatory dysfunction, hyperemia in the acute course of acute coronary syndrome (ACS) may not be optimal $[8,9]$.

Results of currently published studies investigating the use of FFR assessment in ACS are discrepant. Some suggest that measurement of FFR is reliable in ACS, mainly in patients with nonST-elevation myocardial infarction (NSTEMI) [10, 11]; others show differences in FFR values in acute course when compared with FFR assessment after a few weeks or months [12]. Only a few randomized clinical trials (RCT) have been performed showing the efficacy of FFR-guided PCI in ACS. Thus, its role in acute scenarios remains understudied [2].

\section{Clinical aspects of coronary physiology}

Fractional flow reserve is defined as the ratio of pressure measured distally to the stenosis (Pd) to the pressure in the aorta $(\mathrm{Pa})$ under conditions of maximal hyperemia $[5,7,13]$. A body of evidence demonstrates that FFR of $<0.80$ remains the gold standard for the necessity of invasive treatment

Address for correspondence: Dr. Grzegorz Zuk; Dr. Dariusz Ciecwierz, First Department of Cardiology, Medical University of Gdansk, ul. Dębinki 7, 80-952, Gdansk, Poland, e-mail: grzegorz.zuk13@gmail.com; cedario@o2.pl

Received: 17.05.2017 Accepted: 08.06.2017 


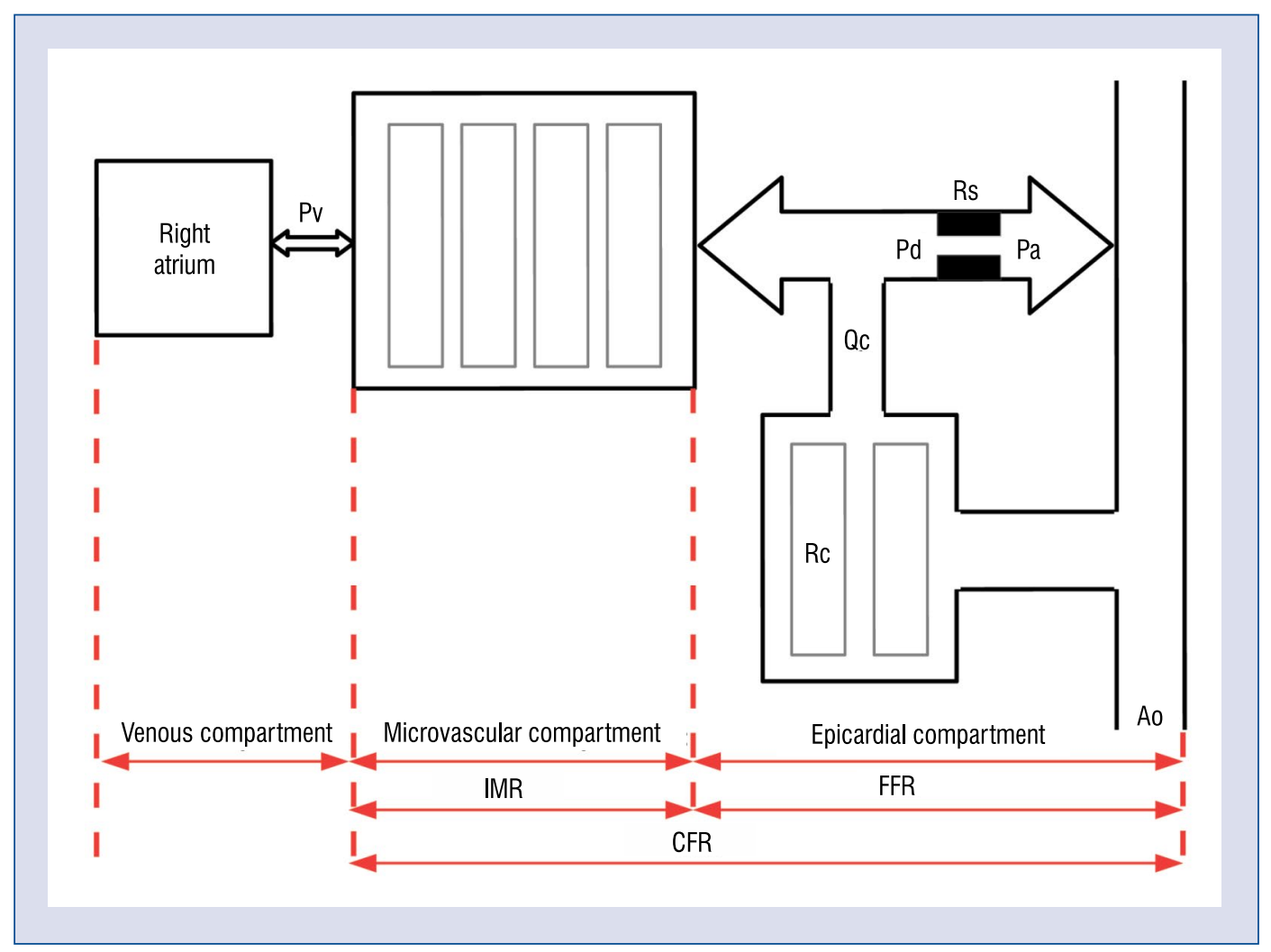

Figure 1. Systemic and coronary vascular beds that influence fractional flow reserve (FFR) [7]; Ao — aortic pressure; $\mathrm{Pa}$ - arterial pressure proximal to stenosis; $\mathrm{Pd}$ - coronary pressure distal to epicardial stenosis; $\mathrm{Pv}$ - venous pressure; Qc - collateral blood flow; Rc - collateral resistance; Rs - epicardial coronary stenosis; IMR — index of microvascular resistance; CFR - coronary flow reserve.

$[14,15]$. However, FFR is only one element when determining whether or not to treat a patient invasively.

Additional parameters that influence the FFR value include the wedge pressure in the coronary arteries $(\mathrm{Pw})$ derived from collateral circulation and venous vessels of the heart as well as venous pressure $(\mathrm{Pv})$, arising from pressure in the right atrium [13]. Myocardial FFR is calculated using the venous pressure $(\mathrm{Pv})$, by the formula FFRmyo = $[\mathrm{Pd}-\mathrm{Pv}] /[\mathrm{Pa}-\mathrm{Pv}]$; in fact, $\mathrm{Pv}$ values are negligible, and in the majority of cases, do not impact the final FFR result [13]. These parameters have not been taken into account in large RCTs with regard to the usefulness of FFR in coronary revascularization (Fig. 1) [3, 4].

\section{Pharmacological hyperemia}

The most widely utilized, and thus, most studied medication used for the induction of hyperemia while assessing FFR is adenosine [16]. It is used primarily intravenously (i.v.), but intracoronary (i.c.) administration of the drug is also permitted. No major differences have been demonstrated in the FFR measurement when comparing the different routes of administration of adenosine [17, 18]. As i.v. adenosine can be used over a longer period; it provides more time in obtaining a reliable measurement. It also has a lower risk of side effects, i.e. arrhythmias [19-21]. Use of adenosine in the assessment of FFR, when given i.v., is done most often as a continuous infusion in the dose $140 \mu \mathrm{g} /$ $/ \mathrm{kg} / \mathrm{min}$, though larger doses are acceptable [16]. When given as an i.c. dose, a bolus is used in the range of 100 to even $500 \mu \mathrm{g}$. Optimal effects are usually achieved at a dose of $200 \mu \mathrm{g}$ to the left coronary artery, and about $100-150 \mu \mathrm{g}$ to the right coronary artery [22]. The bolus may be repeated, simultaneously increasing the dosage of the drug [16]. An essential fact to consider while administering adenosine is the potential usage of caffeine by the patient, which is an antagonist of adenosine 
receptors and may affect the FFR measurement. Matsuomo et al. [23] proved that patients who ingested caffeine within $24 \mathrm{~h}$ prior to FFR measurement had underestimated values of FFR despite requiring larger doses of adenosine, in comparison with those patients who avoided caffeine $>24 \mathrm{~h}$. The FFR values for comparison of the accuracy of FFR measurement were performed using papaverine as the drug to induce hyperemia in this study.

Importantly, bronchial asthma is an absolute contraindication to the use of adenosine as it may cause bronchospasm, which rarely occurs even in patients without known pulmonary disease [24].

Other substances that can be used to induce hyperemia during the measurement of FFR include i.v. regadenoson (agonist of adenosine receptor A2A) [25], i.c. sodium nitroprusside [26], nicorandil [27], nitrates [28] and papaverine [17, 29]. It is important to note that these substances are much less frequently used and thus, do not often appear in the protocols for large RCTs. However, interestingly, when used to produce hyperemia, they do provide a proper and comparative effect [18].

\section{Microvascular resistance is not minimized in recently infarcted myocardium}

As previously mentioned, most of the data to date has been derived from stable CAD subsets. Of note, FFR measurement in ACS may be less reliable due to the limited ability of microcirculation to react to pharmacological vasodilatation, which can lead to false negative results, and underestimate the degree of stenosis, especially in the culprit vessel during STEMI $[8,30]$. However, the FFR-measurement in ACS may prove to be particularly useful in the case of patients with multi-vessel (MVD) CAD. Both in STEMI and NSTEMI, the key point of strategy is to identify the culprit lesion, as revascularization can be postponed in non-culprit vessels. In fact, the one-step full revascularization strategy in non-compromised ACS patients still remains a matter of debate. The most often discussed issue regarding the reliability of FFR in ACS is the area of coronary microvascular dysfunction during an MI. Indeed, the microvascular dysfunction most often affects the area of cardiac muscle supplied by the culprit vessel. However, it can be present throughout the entire myocardium [31, 32]. Experiments on animals show that necrosis and metabolic disorders also affect non-culprit zones [31,32]. Studies performed with the use of positron emission tomography [8], angiography (corrected Thrombolysis in Myocardial Infarction [TIMI] frame count) [33] and Doppler [34] also suggest a widened microvascular dysfunction both in the area of the culprit and non-culprit vessels in patients with STEMI. These processes fundamentally indicate extensive ischemia in adjoining areas of cardiac muscle, vasoconstriction caused by local neurohormonal reactions [35] as well as an increase in the end-diastolic pressure in the left ventricle (LVEDP) [34]. Further studies show that even isolated subendocardial ischemia (which occurs in patients with NSTEMI) can cause an important microvascular dysfunction of the cardiac muscle as a whole [8, 36-40].

The second issue often debated is defining the length of time necessary for microcirculation, if affected in its' entirety, to regain its' function. The amount of time required for microcirculation of the cardiac muscle, if it was impaired, to regain functioning after MI is shown in the literature to last from 7 days to 3 months $[8,41]$ and even up to 6 months [12].

\section{Additional aspects of FFR measurement in patients presenting with ACS}

Fractional flow reserve measurement, whether or not it is justified in MI, does have some disadvantages. Above all, it prolongs the procedure, which is related to the need for additional amounts of contrast and radiation. Patients with stable CAD, when properly informed and prepared for catheterization, physically via hydration, as well as psychologically, they understand the need to prolong the examination for the FFR measurement and are prepared for a longer stay in the cath lab. In patients with ACS, who are often suddenly admitted to the hospital, this fact alone is already a larger stress, and any prolonged testing is associated with additional negative emotions. Additionally, patients are often dehydrated with an unknown status regarding potential kidney dysfunction. The disadvantages of FFR measurement, however, could be outweighed by an advantage, if performing the measurement aids in determining the planned treatment of patients with ACS.

The current standard in functional assessment of the area of non-culprit stenosis is noninvasive testing that is performed during the first few days or weeks after MI. This testing often prolongs hospitalization, can be expensive, and the interpretation of them quickly after an acute 


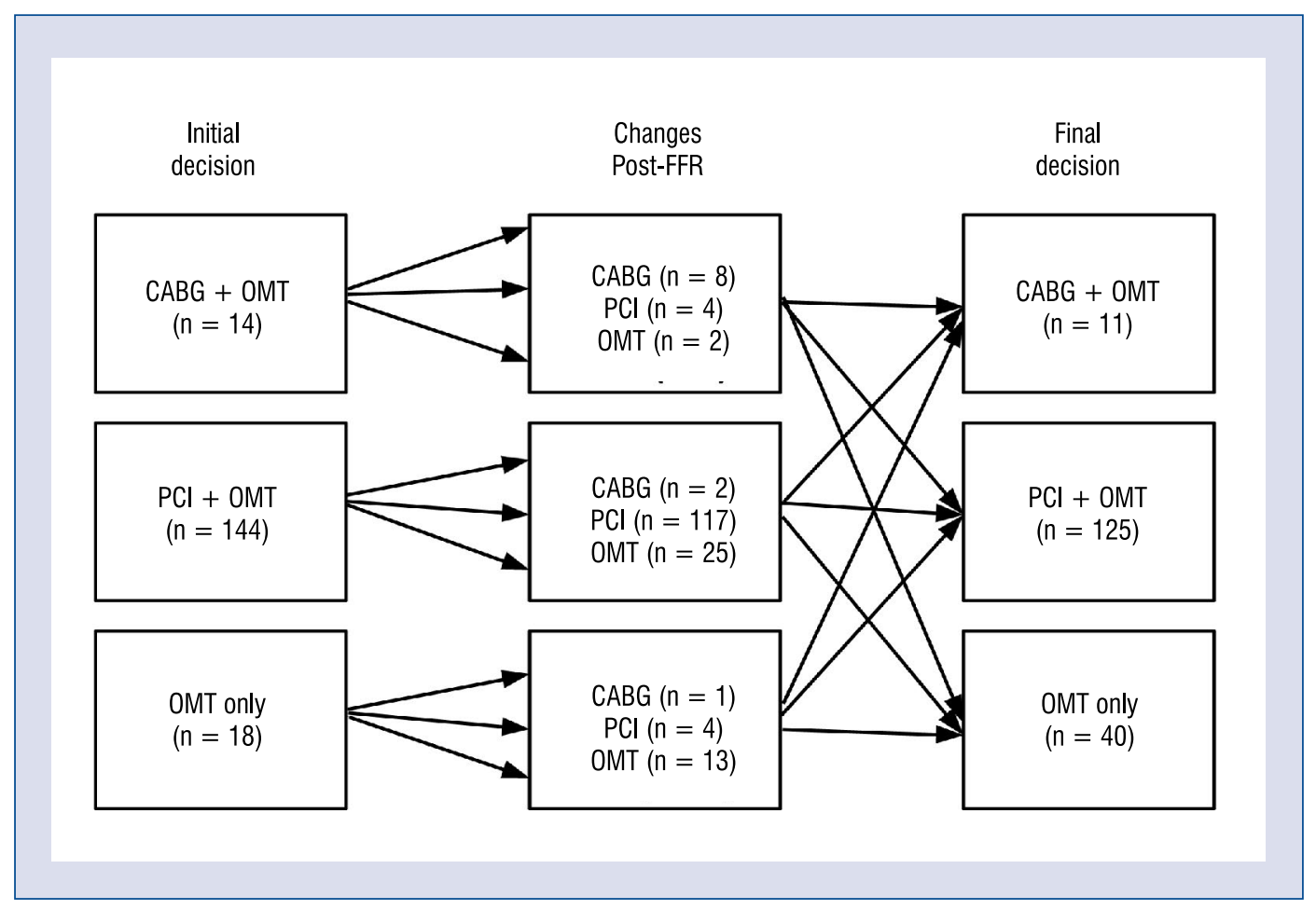

Figure 2. Impact of fractional flow reserve (FFR) disclosure on treatment decisions based on standard angiography-alone in the FAMOUS-NSTEMI clinical trial [11]. CABG - coronary artery bypass graft; OMT — optimal medical therapy; $\mathrm{PCl}$ - percutaneous coronary intervention.

event is ambiguous with regard to whether the patient will require subsequent invasive testing [42]. A body of evidence has described FFR measurement as an interesting and effective diagnostic alternative in patients presenting with ACS and MVD. The main benefits of measuring FFR is that it is reproducible and highly specific. Additionally, this measurement, when performed in experienced centers, can be completed within a few minutes [43].

\section{Landmark Studies of FFR-guided strategy in ACS subsets (Table 1)}

\section{FFR-guided vs. angiographic-guided} management in ACS

The FAMOUS-NSTEMI study compared angiographic assessment with FFR measurements with regards to determining further treatment in non-compromised patients with NSTEMI $[10,11]$. Patients were randomly assigned into one of three groups: coronary artery bypass graft (CABG), PCI or conservative treatment. Interestingly, the use of FFR lowered the need for revascularization. The results of FFR meas- urement in the FFR-guided group changed the method of treatment in 38 patients (Fig. 2). There were essentially no differences between groups regarding major adverse cardiac events (MACE). No cases of adverse drug reactions related to the use of adenosine were recorded. The FAMOUS-NSTEMI $[10,11]$ trial was created on the basis of the FAME trial [3], with the main differences seen in the type of patients who took part in the study (NSTEMI vs. CAD) as well as the degree of stenosis which was assessed (lesions $\geq 30 \%$ vs. $\geq 50 \%$ ) $[10,11]$. A sub-study of FAMOUS-NSTEMI $[10,11]$ compared FFR results with perfusion-magnetic resonance imaging (MRI) studies, and confirmed the diagnostic significance of FFR in stable patients with NSTEMI.

The COMPARE-ACUTE [44] trial compared FFR-guided complete revascularization $(\mathrm{n}=295)$ with culprit artery only revascularization (infarct related artery [IRA], $\mathrm{n}=590$ ) among patients with primary PCI presented with STEMI. Complete revascularization was performed during primary $\mathrm{PCI}$ or as a second procedure no later than $72 \mathrm{~h}$ from admission to the hospital. Significant stenosis 
Table 1. Fractional flow reserve in acute coronary syndrome studies.

\begin{tabular}{|c|c|c|c|c|}
\hline Study & Year & Patients (n) & Aim & Conclusion \\
\hline $\begin{array}{l}\text { Samady } \mathrm{H} \text {, } \\
\text { et al. } \\
\text { JACC } \\
{[48]}\end{array}$ & 2006 & $\begin{array}{l}48 \\
\text { STEMI } \\
\text { NSTEMI }\end{array}$ & $\begin{array}{l}\text { To assess if FFR of IRA early } \\
\text { after MI can be useful in } \\
\text { identifying ischemia on } \\
\text { noninvasive imaging }\end{array}$ & $\begin{array}{l}\text { FFR of the IRA identifies reversibility } \\
\text { on noninvasive imaging early after MI }\end{array}$ \\
\hline $\begin{array}{l}\text { Ntalianis A, } \\
\text { et al. } \\
\text { JACC } \\
\text { [46] }\end{array}$ & 2010 & $\begin{array}{l}101 \\
\text { STEMI } \\
\text { NSTEMI }\end{array}$ & $\begin{array}{l}\text { To examine hemodynamic } \\
\text { severity of the non-culprit } \\
\text { coronary artery stenoses in } \\
\text { the acute phase of } \mathrm{MI}\end{array}$ & $\begin{array}{c}\text { The severity of non-culprit coronary } \\
\text { artery stenoses can be reliably } \\
\text { asseessed by FFR }\end{array}$ \\
\hline $\begin{array}{l}\text { Cuculi F, } \\
\text { et al. } \\
\text { JACC } \\
{[12]}\end{array}$ & 2014 & $\begin{array}{l}82 \\
\text { STEMI }\end{array}$ & $\begin{array}{l}\text { To evaluate of CFR, IMR and } \\
\text { FFR in patients undergoing } \\
\text { primary } \mathrm{PCl} \text { in STEMI }\end{array}$ & $\begin{array}{l}\text { Coronary microcirculation begins } \\
\text { to recover within } 24 \mathrm{~h} \text { and recovery } \\
\text { progresses further for } 6 \text { months after Ml. } \\
\text { FFR significantly reduces from baseline } \\
\text { to } 6 \text { months. The presence } \\
\text { of MVO indicates a highly } \\
\text { microvascular dysfunction }\end{array}$ \\
\hline $\begin{array}{l}\text { Engstrøm T, } \\
\text { et al. } \\
\text { Lancet } \\
\text { [45] }\end{array}$ & 2015 & $\begin{array}{c}627 \\
\text { STEMI }\end{array}$ & $\begin{array}{c}\text { To compare FFR-guided com- } \\
\text { plete revascularization with IRA } \\
\text { among patients undergoing } \\
\text { primary } \mathrm{PCI} \text { for STEMI }\end{array}$ & $\begin{array}{l}\text { No significant difference was found } \\
\text { between the two groups for all-cause } \\
\text { mortality and non-fatal reinfarction } \\
\text { at a median of } 27 \text { months follow-up, } \\
\text { patients in the FFR-guided revasculari- } \\
\text { zation group had significantly fewer } \\
\text { repeat revascularizations }\end{array}$ \\
\hline $\begin{array}{l}\text { Layland J, } \\
\text { et al. } \\
\text { Eur Heart J } \\
{[11]}\end{array}$ & 2015 & $\begin{array}{l}350 \\
\text { NSTEMI }\end{array}$ & $\begin{array}{l}\text { To assess outcomes of } \\
\text { NSTEMI patients assigned to } \\
\text { FFR-guided management or } \\
\text { angiographic-guided } \\
\text { standard care }\end{array}$ & $\begin{array}{l}\text { Angiographic-guided management } \\
\text { was associated with higher rates of } \\
\text { coronary revascularization when } \\
\text { compared with FFR-guided }\end{array}$ \\
\hline $\begin{array}{l}\text { Layland J, } \\
\text { et al. Circ } \\
\text { Cariovasc } \\
\text { Interv } \\
{[47]}\end{array}$ & 2015 & $\begin{array}{c}106 \\
\text { NSTEMI }\end{array}$ & $\begin{array}{c}\text { To assess the diagnostic } \\
\text { accurancy of FFR compared } \\
\text { with } 3.0-T \text { stress CMR perfusion } \\
\text { of NSTEMI patients }\end{array}$ & $\begin{array}{c}\text { FFR in patients with recent NSTEMI } \\
\text { showed high concordance with } \\
\text { myocardial perfusion in matched } \\
\text { territories as revealed by } 3.0-T \text { stress } \\
\text { perfusion CMR }\end{array}$ \\
\hline $\begin{array}{l}\text { Hakeem A, } \\
\text { et al. } \\
\text { JACC } \\
{[50]}\end{array}$ & 2016 & $\begin{array}{l}206 \\
\text { STEMI } \\
\text { NSTEMI }\end{array}$ & $\begin{array}{l}\text { To investigate the clinical and } \\
\text { prognostic utility of FFR in ACS } \\
\text { patients with PCI deferred on } \\
\text { the basis of nonischemic FFR }\end{array}$ & $\begin{array}{l}\text { Deferring } \mathrm{PCl} \text { on the basis of noni- } \\
\text { schemic FFR in patients with ACS is } \\
\text { associated with significantly worse } \\
\text { outcomes than in stable CAD. Caution } \\
\text { is warranted in using FFR values derived } \\
\text { from patients with stable CAD for clini- } \\
\text { cal decision making in ACS patients }\end{array}$ \\
\hline $\begin{array}{l}\text { Ahmed N, } \\
\text { et al. } \\
\text { Int J Cardiol } \\
{[54]}\end{array}$ & 2016 & $\begin{array}{l}648 \\
\text { STEMI } \\
\text { NSTEMI }\end{array}$ & $\begin{array}{l}\text { To assess the safety of guide- } \\
\text { wire-based measurement of } \\
\text { coronary physiology using i.v. } \\
\text { adenosine in patients with ACS }\end{array}$ & $\begin{array}{l}\text { Guidewire-based measurement of } \\
\text { FFR and IMR using i.v. adenosine } \\
\text { was safe in patients with ACS }\end{array}$ \\
\hline $\begin{array}{l}\text { Smits PC, } \\
\text { et al. } \\
\text { N Engl J Med } \\
{[44]}\end{array}$ & 2017 & $\begin{array}{c}885 \\
\text { STEMI }\end{array}$ & $\begin{array}{l}\text { To evaluate FFR-guided } \\
\text { complete revascularization } \\
\text { compared with IRA among } \\
\text { patients undergoing } \\
\text { primary PCI for STEMI }\end{array}$ & $\begin{array}{l}\text { FFR-guided complete revascularization } \\
\text { during the index procedure } \\
\text { was superior to IRA }\end{array}$ \\
\hline
\end{tabular}

ACS - acute coronary syndrome; CAD - coronary artery disease; CFR - coronary flow reserve; CMR - cardiovascular magnetic resonance imaging; FFR - fractional flow reserve; i.v. - intravenously; IMR - microcirculatory resistance; IRA — infarct related artery; MI myocardial infarction; MVO - microvascular obstruction; NSTEMI - non-ST-elevation myocardial infarction; PCl - percutaneous coronary intervention; STEMI - ST-elevation myocardial infarction

of the non-culprit vessel was considered $\geq 50 \%$ stenosis. It turned out that in STEMI patients, FFR-guided compete revascularization was superior to the IRA group in MACE points at 12 months observation (7.8\% vs. $20.5 \%, \mathrm{p}<0.001)$. It is worth emphasizing that there were no differences in MI and mortality. Most importantly, that patients in the IRA group had more re-PCIs when compared 
with the FFR-guided complete revascularization group $(17.5 \%$ vs. $6.1 \%, \mathrm{p}<0.001)$. As in most of cases, complete revascularization was performed during the primary procedure, thus there were less MACEs in the complete FFR-guided revascularization. Similarly, no significant difference in MACE was recorded in the DANAMI-3-PRIMULTI trial [45] after a 27-month follow-up, where STEMI patients $(n=627)$ were randomly assigned $(1: 1)$ to IRA group and FFR-guided complete revascularization group. Again, there was a significantly lower rate of further revascularization in the FFR-guided complete revascularization group.

\section{Reliability of FFR assessment in ACS}

Ntalianis et al. [46] were the first to assess the reliability of FFR measurement in patients with ACS. Non-culprit stenosis $(\mathrm{n}=112)$ in the range of \%DS (diameter stenosis) 30-90\%, were evaluated, with FFR measurements taken immediately after PCI of the culprit lesion. The FFR measurement was obtained and compared at $35 \pm 4$ days. Additionally, left ventricular ejection fraction, quantitative coronary angiography, flow according to TIMI scale and the index of microcirculatory resistance (IMR) were assessed in fourteen patients $(n=14)$, during both the acute phase and follow-up. The FFR measurements did not significantly differ between the acute phase and follow-up examinations $(0.77 \pm 0.13$ vs. $0.77 \pm 0.13, p=N S)$. In 2 patients, the FFR value was $>0.80$ during the time of MI and was $<0.75$ in follow-up. In the remaining examined parameters, no statistically significant differences were noted. The key conclusion of this study is that the measurement of FFR in non-culprit stenoses of patients with MI, can be performed in a reliable manner during the acute phase of the disease and allows for planning of a more appropriate strategy of individualized treatment for each patient.

Notably, the study did have a few limitations which may have affected the results and derived conclusions. The main dilemma is the length of the observational period and timing of the control angiography with FFR measurement. In the initial study parameters, this period was set for 3 months, but was at most $35 \pm 4$ days. Accordingly, the measurements conducted theoretically in the stable phase of disease may have been performed during the period when microcirculation was still dysfunctional, thus, inducing hyperemia was still not possible. This could lead to FFR measurements being exaggerated, and correlating closer with the results obtained in the acute phase of the disease. The second limitation of the study was the dosage of adenosine. In the majority of patients, the drug was administered i.c. $(\mathrm{n}=87)$ in a dose of $50 \mu \mathrm{g}$ [22]. This dose may not have been enough to induce hyperemia especially during the followup period when theoretically, the microcirculation could already be functional. Using such a small dose could cause the results obtained to be essentially unreliable.

\section{FFR assessment vs. noninvasive imaging in ACS subset}

Layland et al. [47], in the substudy of FAMOUS-NSTEMI, compared FFR measurements in patients with NSTEMI to results obtained via 3-T cardiovascular magnetic resonance imaging (CMR) $(\mathrm{n}=106)$. Measurements of FFR were performed in all lesions of $\geq 30 \%$. In cases where PCI was performed, the FFR measurement was repeated. Sensitivity, specificity, positive predictive value and negative predictive value for FFR $\leq 0.80$ amounted to $91.4 \%, 92.2 \%, 76 \%, 97 \%$, respectively. In patients who had CMR performed prior to coronary angiography $(n=21)$, the positive and negative predictive value for $\mathrm{FFR} \leq 0.80$ was $92 \%$ and $93 \%$, respectively. On the basis of these results, an optimal cut-off point for FFR measurement was determined, representing an ischemia in CMR at the level $\leq 0.805$. A similar study was conducted by Samady et al. [48], of 48 hemodynamically stable patients with recent MI, comparing the FFR measurement in the culprit lesion with results obtained from single photon emission computed tomography (SPECT) as well as those from echocardiography with the use of contrast. The average time from angiography to noninvasive examination amounted to 3.7 days, with $73 \%$ of patients diagnosed with STEMI. It was concluded that a result of FFR $\leq 0.75$ showed $91 \%$ sensitivity, $93 \%$ specificity, as well as a diagnostic accuracy at the level of $92 \%$ for identifying reversible ischemia. Interestingly, the optimal cut-off for FFR measurement to accurately determine ischemia was $\leq 0.78$.

\section{Microvascular function and FFR in ACS}

Cuculi et al. [12] aimed to grade the dynamic changes in coronary flow reserve (CFR), the index of IMR, and the FFR in patients who underwent primary PCI in STEMI $(n=82)$. Assessment of FFR was performed only within the culprit lesion, after the previous PCI. A second invasive measurement of coronary physiology was conducted the 
first day after invasive treatment of MI $(n=61)$, or 6 months later $(n=46)$.

Contrast-enhanced MRI was performed during the first day of treatment $(n=45)$ or after 6 months $(n=41)$. Patients were divided into two groups, those with and those without microvascular obstruction (MVO) of cardiac muscle confirmed via CMR. MVO was recognized in $21(47 \%)$ patients. FFR measurements were significantly lower after 6 months in comparison to FFR measurements obtained during the initial PCI $(p=0.008)$. This phenomenon was seen mainly in those with confirmed MVO $(p=0.006)$. The MVO patient group was found to have a lower CFR $(\mathrm{p}<0.05)$ and a higher IMR $(\mathrm{p}=0.07)$ in their initial measurements (first $\mathrm{PCI}$ and first day) in comparison to the group of patients without MVO. However, in the results obtained after 6 months, there were no differences between the two groups with regard to CFR and IMR. It appears that in some patients with STEMI, a temporary dysfunction of cardiac muscle vasculature does occur, and the process of returning this muscle to a state of complete recovery can last up to 6 months. The presence of MVO causes a significant dysfunction related to a limited response to adenosine. Accordingly, FFR measurements obtained during ACS may underestimate the degree of stenosis in about half of STEMI patients.

Authors of the above-presented study claim that the process of healing the damaged microcirculation can last up to 6 months post infarction. However, it is likely that the CFR, IMR and FFR results are similar much earlier, for instance, within 3 months $[8,49]$. So far, this issue has no exact answer and thus, further studies to identify the most optimal period for the restoration of microcirculation are still warranted.

\section{Do we need other cut-off point for FFR assessment in ACS?}

One of the latest publications regarding FFR assessment in ACS is the work by Hakeem et al. [50] where patients with NSTE-ACS ( $\mathrm{n}=206$, 262 intermediate stenoses) were compared to patients with stable CAD $(\mathrm{n}=370)$ with border stenoses in coronary arteries $(\mathrm{n}=528)$, who were disqualified from PCI after obtaining an FFR $>0.75$. They compared the frequency of MI and the need for target vessel revascularization (TVR) over a 3.4 year period of observation. It became apparent that the rate of MI and TVR was higher in the NSTE-ACS group (25\% vs. $12 \% ; \mathrm{p}<0.0001)$, as seen in the literature [51, 52]. The optimal cut-off point for significant stenosis in patients with CAD was determined to be an FFR measurement of $\leq 0.80$, while in patients with NSTE-ACS, a measurement of $\leq 0.84$ was noted. One must take into account that the results of the second group may be falsely negative due to microvascular dysfunction. As such, one of the main conclusions of the study is the recommendation that patients with NSTE-ACS, FFR results between 0.80 and 0.85 fall into a gray zone and should be confirmed before planning further treatment strategy. Given this study's conclusions, one must consider whether FFR assessment in patients with ACS requires a different cut-off point than that of patients with CAD.

It is important to touch upon some of the limitations of this study, starting with the fact that the position of the FFR wire during measurement was never mentioned [53]. Secondly, in at least half of the patients, adenosine was given ic. in a dose of only $130 \mu \mathrm{g}$, and in some, even at $60 \mu \mathrm{g}$, which could lead to suboptimal hyperemia. The third limitation of the study is that only patients with NSTE-ACS and border angiographic lesions were included. Thus, some amount of patients enrolled into the study might have elevated troponin levels due to other reasons and not essentially myocardial ischemia.

\section{Safety of FFR measurement in ACS}

Problems during FFR assessment are often a result of the medications used to induce hyperemia, most commonly adenosine. Adenosine causes above all, transient disturbances in atrioventricular conduction, and rarely, ventricular arrhythmias, which occur more commonly when given i.c. $[16,17]$. Application of the drug is associated with a benign sensation of discomfort in the chest, which quickly dissipates, with no negative consequences. A more serious problem that occurs is the mechanical damage to the vessel wall by the catheter used to measure the FFR and pressure wire. Although a rare occurrence, it can lead to dissection of the vessel, and, in extreme cases, perforation [54].

\section{Limitations of FFR assessment in ACS}

Acute coronary syndrome in contrast to CAD is more frequently associated with various factors 
that could prevent FFR measurement. As a result, these factors are deemed significant contraindications to performing the procedure; they include bradycardia, hypotension, hemodynamic instability or severe arrhythmias. Last but not least, the FFR-measurement is often not possible when the vessel is occluded completely or critically stenosed with delayed collateral circulation [49].

\section{Conclusions and future perspectives}

Only a few RCT have been performed showing the efficacy of FFR-guided PCI in ACS Thus, its role in acute scenarios is clearly understudied.

Although the clinical relevance of FFR-measurement in acute course of ACS still remains controversial, it appears that use of FFR could prove to be an excellent tool to assess the significance of non-culprit stenosis especially in a setting of NSTEMI and MVD. Consequently, the entire plan of the treatment strategy of a patient could be determined already during the first angiographic procedure. Reliable tools to aid in the assessment of non-culprit lesions during the initial coronary intervention could significantly impact treatment strategies in patients with MI. An early evaluation of the area of cardiac muscle at risk of ischemia could lead to better risk stratification and a more adequate qualification of patients for further revascularization. On the other hand, FFR assessment of non-culprit lesions in the acute phase of MI could prove to be inaccurate with regards to microvascular dysfunction and the challenges of obtaining optimal conditions for this examination [30,55]. Easily, this could lead to an underestimation or overestimation of the severity of stenosis, which as a consequence, could result in choosing a suboptimal type of therapy [55-57]. Most recently in the literature, it has been shown that revascularization of functionally significant non-culprit stenoses within the first month after $\mathrm{MI}$ is associated with a better long-term outcome. In contrast, non-culprit lesions that are not significant rarely display signs of progression [34]. Taking this into account, it can be easily predicted how important a role FFR measurements could play in the assessment of significant non-culprit stenoses in ACS, and at the same time, impact the approach to patient management.

There is little doubt, that the assessment of FFR in patients with ACS certainly demands further RCTs to accurately confirm or deny the importance of performing FFR measurements during the acute phase of MI. FFR has a chance of becoming an essential tool for physicians not only in stable CAD, as it is currently used, but also during PCI of patients with ACS. This topic requires further analysis and more refined trials on a broader group of patients, to allow for complete confidence in confirming the reliability of FFR measurements obtained in patients with ACS.

The potential clinical utility of a FFR-guided management in ACS patients with MVD is still being studied in COMPLETE STUDY, FULL REVASC and PRAMI-2 trials.

\section{Conflict of interest: None declared}

\section{References}

1. Montalescot G, Sechtem U, Achenbach S, et al. Task Force Members, ESC Committee for Practice Guidelines, Document Reviewers. 2013 ESC guidelines on the management of stable coronary artery disease: the Task Force on the management of stable coronary artery disease of the European Society of Cardiology. Eur Heart J. 2013; 34(38): 2949-3003, doi: 10.1093/ eurheartj/eht296, indexed in Pubmed: 23996286.

2. Windecker S, Kolh P, Alfonso F, et al. Authors/Task Force members. 2014 ESC/EACTS Guidelines on myocardial revascularization: The Task Force on Myocardial Revascularization of the European Society of Cardiology (ESC) and the European Association for Cardio-Thoracic Surgery (EACTS)Developed with the special contribution of the European Association of Percutaneous Cardiovascular Interventions (EAPCI). Eur Heart J. 2014; 35(37): 2541-2619, doi: 10.1093/eurheartj/ehu278, indexed in Pubmed: 25173339.

3. Tonino P, Bruyne BDe, Pijls N, et al. Fractional flow reserve versus angiography for guiding percutaneous coronary intervention. N Engl J Med. 2009; 360(3): 213-224, doi: 10.1056/ nejmoa0807611.

4. De Bruyne B, Pijls NHJ, Kalesan B, et al. FAME 2 Trial Investigators. Fractional flow reserve-guided PCI versus medical therapy in stable coronary disease. N Engl J Med. 2012; 367(11): 991-1001, doi: 10.1056/NEJMoa1205361, indexed in Pubmed: 22924638.

5. Pijls NH, De Bruyne B. Coronary Pressure. 2nd Ed. Kluwer Academic Publishers, The Netherlands: 2000.

6. Spaan JAE, Piek JJ, Hoffman JIE, et al. Physiological basis of clinically used coronary hemodynamic indices. Circulation. 2006; 113(3): 446-455, doi:10.1161/CIRCULATIONAHA.105.587196, indexed in Pubmed: 16432075.

7. Pijls NH, van Son JA, Kirkeeide RL, et al. Experimental basis of determining maximum coronary, myocardial, and collateral blood flow by pressure measurements for assessing functional stenosis severity before and after percutaneous transluminal coronary angioplasty. Circulation. 1993; 87(4): 1354-1367, indexed in Pubmed: 8462157.

8. Uren NG, Crake T, Lefroy DC, et al. Reduced coronary vasodilator function in infarcted and normal myocardium after myocardial infarction. N Engl J Med. 1994; 331(4): 222-227, doi: 10.1056/ NEJM199407283310402, indexed in Pubmed: 7832835. 
9. Ragosta M, Powers ER, Samady H, et al. Relationship between extent of residual myocardial viability and coronary flow reserve in patients with recent myocardial infarction. Am Heart J. 2001; 141(3): 456-462, doi: 10.1067/mhj.2001.113074, indexed in Pubmed: 11231445.

10. Berry C, Layland J, Sood A, et al. Fractional flow reserve versus angiography in guiding management to optimize outcomes in non-ST-elevation myocardial infarction (FAMOUS-NSTEMI): rationale and design of a randomized controlled clinical trial. Am Heart J. 2013; 166(4): 662-668.e3, doi:10.1016/j.ahj.2013.07.011, indexed in Pubmed: 24093845.

11. Layland J, Oldroyd KG, Curzen N, et al. FAMOUS-NSTEMI investigators. Fractional flow reserve vs. angiography in guiding management to optimize outcomes in non-ST-segment elevation myocardial infarction: the British Heart Foundation FAMOUSNSTEMI randomized trial. Eur Heart J. 2015; 36(2): 100-111, doi: 10.1093/eurheartj/ehu338, indexed in Pubmed: 25179764.

12. Cuculi F, De Maria GL, Meier P, et al. Impact of microvascular obstruction on the assessment of coronary flow reserve, index of microcirculatory resistance, and fractional flow reserve after ST-segment elevation myocardial infarction. J Am Coll Cardiol. 2014; 64(18): 1894-1904, doi:10.1016/j.jacc.2014.07.987, indexed in Pubmed: 25444143.

13. De Bruyne B, Baudhuin T, Melin JA, et al. Coronary flow reserve calculated from pressure measurements in humans. Validation with positron emission tomography. Circulation. 1994; 89(3): 1013-1022, indexed in Pubmed: 8124786.

14. Toth G, Hamilos M, Pyxaras S, et al. Evolving concepts of angiogram: fractional flow reserve discordances in 4000 coronary stenoses. Eur Heart J. 2014; 35(40): 2831-2838, doi: 10.1093/ eurheartj/ehu094, indexed in Pubmed: 24644308.

15. Pijls NH, De Bruyne B, Peels K, et al. Measurement of fractional flow reserve to assess the functional severity of coronary-artery stenoses. N Engl J Med. 1996; 334(26): 1703-1708, doi: 10.1056/ NEJM199606273342604, indexed in Pubmed: 8637515.

16. Layland J, Carrick D, Lee M, et al. Adenosine: physiology, pharmacology, and clinical applications. JACC Cardiovasc Interv. 2014; 7(6): 581-591, doi:10.1016/j.jcin.2014.02.009, indexed in Pubmed: 24835328.

17. De Bruyne B, Pijls NHJ, Barbato E, et al. Intracoronary and intravenous adenosine 5'-triphosphate, adenosine, papaverine, and contrast medium to assess fractional flow reserve in humans. Circulation. 2003; 107(14): 1877-1883, doi: 10.1161/01. CIR.0000061950.24940.88, indexed in Pubmed:12668522.

18. Lim WH, Koo BK, Nam CW, et al. Variability of fractional flow reserve according to the methods of hyperemia induction. Catheter Cardiovasc Interv. 2014; 85(6): 970-976, doi: 10.1002/ccd.25752.

19. Seto AH, Tehrani DM, Bharmal MI, et al. Variations of coronary hemodynamic responses to intravenous adenosine infusion: implications for fractional flow reserve measurements. Catheter Cardiovasc Interv. 2014; 84(3): 416-425, doi: 10.1002/ccd.25305, indexed in Pubmed: 24282074.

20. Echavarria-Pinto M, Petraco R, van de Hoef TP, et al. Fractional flow reserve and minimum $\mathrm{Pd} / \mathrm{Pa}$ ratio during intravenous adenosine infusion: very similar but not always the same. EuroIntervention. 2016; 11(9): 1013-1019, doi: 10.4244/EIJY14M10_09, indexed in Pubmed: 25366652.

21. Tarkin JM, Nijjer S, Sen S, et al. Hemodynamic response to intravenous adenosine and its effect on fractional flow reserve assessment: results of the Adenosine for the Functional Evaluation of Coronary Stenosis Severity (AFFECTS) study. Circ
Cardiovasc Interv. 2013; 6(6): 654-661, doi:10.1161/CIRCINTERVENTIONS.113.000591, indexed in Pubmed: 24254709.

22. Adjedj J, Toth GG, Johnson NP, et al. Intracoronary Adenosine: Dose-Response Relationship With Hyperemia. JACC Cardiovasc Interv. 2015; 8(11): 1422-1430, doi: 10.1016/j.jcin.2015.04.028, indexed in Pubmed: 26404193.

23. Matsumoto H, Nakatsuma K, Shimada T, et al. Effect of caffeine on intravenous adenosine-induced hyperemia in fractional flow reserve measurement. J Invasive Cardiol. 2014; 26(11): 580-585, indexed in Pubmed: 25363999.

24. Coli S, Mantovani F, Ferro J, et al. Adenosine-induced severe bronchospasm in a patient without pulmonary disease. Am J Emerg Med. 2012; 30(9): 2082.e3-2082.e5, doi: 10.1016/j. ajem.2011.11.005, indexed in Pubmed: 22177587.

25. van Nunen LX, Lenders GD, Schampaert S, et al. Single bolus intravenous regadenoson injection versus central venous infusion of adenosine for maximum coronary hyperaemia in fractional flow reserve measurement. EuroIntervention. 2015; 11(8): 905913, doi: 10.4244/EIJY14M08_10, indexed in Pubmed: 25136887.

26. Rudzinski W, Waller AH, Rusovici A, et al. Comparison of efficacy and safety of intracoronary sodium nitroprusside and intravenous adenosine for assessing fractional flow reserve. Catheter Cardiovasc Interv. 2013; 81(3): 540-544, doi: 10.1002/ccd.24652, indexed in Pubmed: 22961876.

27. Jang HJ, Koo BK, Lee HS, et al. Safety and efficacy of a novel hyperaemic agent, intracoronary nicorandil, for invasive physiological assessments in the cardiac catheterization laboratory. Eur Heart J. 2013; 34(27): 2055-2062, doi: 10.1093/eurheartj/ eht040, indexed in Pubmed: 23396491.

28. Martin-Reyes R, de la Torre Hernandez JM, Franco-Pelaez J, et al. The use of the acute $\mathrm{Pd} / \mathrm{Pa}$ drop after intracoronary nitroglycerin infusion to rule out significant FFR: CANICA (Can intracoronary nitroglycerin predict fractional flow reserve without adenosine?) multicenter study. Catheter Cardiovasc Interv. 2016; 87(2): $262-$ -269, doi: 10.1002/ccd.25983, indexed in Pubmed: 26213338.

29. Kern M, Deligonul U, Tatineni S, et al. Intravenous adenosine: continuous infusion and low dose bolus administration for determination of coronary vesodilatator reserve in patients with and without coronary artery disease. J Ann Coll Cardiol. 1991; 18(3): 718-729, doi: 10.1016/0735-1097(91)90795-b.

30. Ragosta M, Powers ER, Samady H, et al. Relationship between extent of residual myocardial viability and coronary flow reserve in patients with recent myocardial infarction. Am Heart J. 2001; 141(3): 456-462, doi: 10.1067/mhj.2001.113074, indexed in Pubmed: 11231445.

31. Wyatt HL, Forrester JS, da Luz PL, et al. Functional abnormalities in nonoccluded regions of myocardium after experimental coronary occlusion. Am J Cardiol. 1976; 37(3): 366-372, indexed in Pubmed: 1258769.

32. Corday E, Kaplan L, Meerbaum S, et al. Consequences of coronary arterial occlusion on remote myocardium: effects of occlusion and reperfusion. Am J Cardiol. 1975; 36(3): 385-394, indexed in Pubmed: 1166843.

33. Sorajja P, Gersh BJ, Cox DA, et al. Impact of multivessel disease on reperfusion success and clinical outcomes in patients undergoing primary percutaneous coronary intervention for acute myocardial infarction. Eur Heart J. 2007; 28(14): 1709-1716, doi: 10.1093/eurheartj/ehm184, indexed in Pubmed: 17556348.

34. Van Herck PL, Carlier SG, Claeys MJ, et al. Coronary microvascular dysfunction after myocardial infarction: increased coronary zero flow pressure both in the infarcted and in the remote 
myocardium is mainly related to left ventricular filling pressure. Heart. 2007; 93(10): 1231-1237, doi:10.1136/hrt.2006.100818, indexed in Pubmed: 17395671.

35. Gregorini L, Marco J, Kozàkovà M, et al. Alpha-adrenergic blockade improves recovery of myocardial perfusion and function after coronary stenting in patients with acute myocardial infarction. Circulation. 1999; 99(4): 482-490, indexed in Pubmed: 9927393.

36. Sambuceti G, Marzullo P, Giorgetti A, et al. Global alteration in perfusion response to increasing oxygen consumption in patients with single-vessel coronary artery disease. Circulation. 1994; 90(4): 1696-1705, indexed in Pubmed: 7923653.

37. Wu JC, Yun JJ, Dione DP, et al. Severe regional ischemia alters coronary flow reserve in the remote perfusion area. J Nucl Cardiol. 2000; 7(1): 43-52, doi: 10.1067/mnc.2000.99189, indexed in Pubmed: 10698234.

38. Pacella JJ, Villanueva FS. Effect of coronary stenosis on adjacent bed flow reserve: assessment of microvascular mechanisms using myocardial contrast echocardiography. Circulation. 2006; 114(18): 1940-1947, doi: 10.1161/CIRCULATIONAHA.106.641779, indexed in Pubmed: 17060378.

39. Nichols WW, Nicolini FA, Yang B, et al. Attenuation of coronary flow reserve and myocardial function after temporary subtotal coronary artery occlusion and increased myocardial oxygen demand in dogs. J Am Coll Cardiol. 1994; 24(3): 795-803, indexed in Pubmed: 8077555.

40. Marques KM, Knaapen P, Boellaard R, et al. Hyperaemic microvascular resistance is not increased in viable myocardium after chronic myocardial infarction. Eur Heart J. 2007; 28(19): 2320-2325, doi: 10.1093/eurheartj/ehm309, indexed in Pubmed: 17656351.

41. Kramer CM, Rogers WJ, Theobald TM, et al. Remote noninfarcted region dysfunction soon after first anterior myocardial infarction. A magnetic resonance tagging study. Circulation. 1996; 94(4): 660-666, indexed in Pubmed: 8772685.

42. Leesar MA, Abdul-Baki T, Akkus NI, et al. Use of fractional flow reserve versus stress perfusion scintigraphy after unstable angina. Effect on duration of hospitalization, cost, procedural characteristics, and clinical outcome. J Am Coll Cardiol. 2003; 41(7): 1115-1121, indexed in Pubmed: 12679210.

43. De Bruyne B, Sarma J. Fractional flow reserve: a review: invasive imaging. Heart. 2008; 94(7): 949-95x9, doi: 10.1136/ hrt.2007.122838, indexed in Pubmed: 18552231.

44. Smits P, Abdel-Wahab M, Neumann FJ, et al. Fractional flow reserve-guided multivessel angioplasty in myocardial infarction. New Engl J Med. 2017; 376(13): 1234-1244, doi: 10.1056/ nejmoa1701067.

45. Engstrøm T, Kelbæk H, Helqvist S, et al. DANAMI-3-PRIMULTI Investigators. Complete revascularisation versus treatment of the culprit lesion only in patients with ST-segment elevation myocardial infarction and multivessel disease (DANAMI-3-PRIMULTI): an open-label, randomised controlled trial. Lancet. 2015; 386(9994): 665-671, indexed in Pubmed: 26347918.

46. Ntalianis A, Sels JW, Davidavicius G, et al. Fractional flow reserve for the assessment of nonculprit coronary artery stenoses in patients with acute myocardial infarction. JACC Cardiovasc Interv. 2010; 3(12): 1274-1281, doi: 10.1016/j.jcin.2010.08.025, indexed in Pubmed: 21232721.
47. Layland J, Rauhalammi S, Watkins S, et al. Assessment of Fractional Flow Reserve in Patients With Recent Non-ST-SegmentElevation Myocardial Infarction: Comparative Study With 3-T Stress Perfusion Cardiac Magnetic Resonance Imaging. Circ Cardiovasc Interv. 2015; 8(8): e002207, doi:10.1161/CIRCINTERVENTIONS.114.002207, indexed in Pubmed: 26253733.

48. Samady H, Lepper W, Powers ER, et al. Fractional flow reserve of infarct-related arteries identifies reversible defects on noninvasive myocardial perfusion imaging early after myocardial infarction. J Am Coll Cardiol. 2006; 47(11): 2187-2193, doi: 10.1016/j.jacc.2006.01.065, indexed in Pubmed:16750683.

49. Cuculi F, De Maria GL, Meier P, et al. Impact of microvascular obstruction on the assessment of coronary flow reserve, index of microcirculatory resistance, and fractional flow reserve after ST-segment elevation myocardial infarction. J Am Coll Cardiol. 2014; 64(18): 1894-1904, doi:10.1016/j.jacc.2014.07.987, indexed in Pubmed: 25444143.

50. Hakeem A, Edupuganti MM, Almomani A, et al. Long-Term prognosis of deferred acute coronary syndrome lesions based on nonischemic fractional flow reserve. J Am Coll Cardiol. 2016; 68(11): 1181-1191, doi: 10.1016/j.jacc.2016.06.035, indexed in Pubmed: 27609680.

51. Morrow DA. Cardiovascular risk prediction in patients with stable and unstable coronary heart disease. Circulation. 2010; 121(24): 2681-2691, doi:10.1161/CIRCULATIONAHA.109.852749, indexed in Pubmed: 20566966.

52. Mahaffey KW, Wojdyla DM, Pieper KS, et al. Comparison of clinical trial outcome patterns in patients following acute coronary syndromes and in patients with chronic stable atherosclerosis. Clin Cardiol. 2014; 37(6): 337-342, doi: 10.1002/clc.22255, indexed in Pubmed: 24615711.

53. Rodés-Cabau J, Gutiérrez M, Courtis J, et al. Importance of diffuse atherosclerosis in the functional evaluation of coronary stenosis in the proximal-mid segment of a coronary artery by myocardial fractional flow reserve measurements. Am J Cardiol. 2011; 108(4): 483-490, doi:10.1016/j.amjcard.2011.03.073, indexed in Pubmed: 21624549.

54. Ahmed N, Layland J, Carrick D, et al. Safety of guidewire-based measurement of fractional flow reserve and the index of microvascular resistance using intravenous adenosine in patients with acute or recent myocardial infarction. Int J Cardiol. 2016; 202: 305-310, doi:10.1016/j.ijcard.2015.09.014, indexed in Pubmed: 26418191.

55. White CW, Wright CB, Doty DB, et al. Does visual interpretation of the coronary arteriogram predict the physiologic importance of a coronary stenosis? N Engl J Med. 1984; 310(13): 819-824, doi: 10.1056/NEJM198403293101304, indexed in Pubmed: 6700670.

56. Tonino PAL, Fearon WF, De Bruyne B, et al. Angiographic versus functional severity of coronary artery stenoses in the FAME study fractional flow reserve versus angiography in multivessel evaluation. J Am Coll Cardiol. 2010; 55(25): 2816-2821, doi: 10.1016/j.jacc.2009.11.096, indexed in Pubmed: 20579537.

57. Selby JV, Fireman BH, Lundstrom RJ, et al. Variation among hospitals in coronary-angiography practices and outcomes after myocardial infarction in a large health maintenance organization. N Engl J Med. 1996; 335(25): 1888-1896, doi: 10.1056/ NEJM199612193352506, indexed in Pubmed: 8948565. 